Research Article

www.ijrap.net

\title{
ACUTE ANTI-INFLAMMATROY ACTIVITY OF ETHANOLIC EXTRACT OF LEAVES OF CLERODENDRUM VISCOSUM BY CARRAGEENIN INDUCED PAW OEDEMA METHOD IN WISTAR ALBINO RATS
}

\author{
Chandrashekar R.*, Rao S.N \\ Department of Pharmacology, Yenepoya Medical College, Yenepoya University, Derlakatte, Mangalore, Karnataka, \\ India
}

Received on: 06/12/12 Revised on: 17/01/13 Accepted on: 10/02/13

\author{
*Corresponding author \\ E-mail: chandumoon47@gmail.com \\ DOI: $10.7897 / 2277-4343.04227$ \\ Published by Moksha Publishing House. Website www.mokshaph.com \\ All rights reserved.
}

\section{ABSTRACT}

Inflammation is an important feature of many diseases. It is the response of a tissue to an injury, infection, irritation of foreign substance. In fact, it is a part of host defense, but when it is severe, it may be far worse than the diseases itself and in extreme condition, it may be too fatal also. There is an increasing demand for the medicinal plants in developing countries like India. Attention has to be given to assess the medicinal value of such plants to explore the potential drugs out of it. The aim of the study was to investigate acute anti-inflammatory activity of ethanolic extract of the leaves of Clerodendrum viscosum (EELCV) by carrageenin induced paw oedema in Wistar Albino rats. Dried powdered leaves of Clerodendrum viscosum were subjected to soxhlet extraction by using $90 \%$ ethanol. Based on acute oral toxicity study according to Organization for Economic Cooperation and Development (OECD) guidelines No. 423, three doses of the test drug were selected (75, $150 \mathrm{and} 300 \mathrm{mg} / \mathrm{kg}$ p.o). Oral administration of EELCV at doses of 150 and $300 \mathrm{mg} / \mathrm{kg}$ showed significant $(\mathrm{p}<0.01)$ and moderately significant acute anti-inflammatory activity $(\mathrm{p}<0.05)$ respectively by carrageenin induced paw oedema in Wistar Albino rats compared to control.

Keywords: Anti-inflammatory activity, Clerodendrum viscosum, Carrageenin, Indomethacin.

\section{INTRODUCTION}

Pain and inflammation are the most common symptoms of many diseases afflicting millions of people worldwide. ${ }^{1,2}$ Even though there are effective medicines used to reduce these manifestations, ${ }^{3}$ traditional medicine practitioners, mainly in developing countries have been using herbal medicines to treat various ailments including pain and inflammation. ${ }^{4}$ Nature has provided a complete store-house of natural remedies to cure many aliments. ${ }^{5}$ This is where, nature ${ }^{6}$ provides us a good source in the form of herbs, plants, algae's etc to cure many diseases without much toxic effects. Research on medicinal plants is an important field of biochemical research in India. ${ }^{7}$ Inflammation is a manifestation involved in localized increase in the number of leukocytes and a variety of complex inflammatory mediators. It also involves synthesis and release of prostaglandins at injured site of inflammation. Medicinal plants are believed to be an important source of new chemical substances with potential therapeutic effects. The research on plants with age old folkloric used as pain relievers, anti-inflammatory agents, and therefore be considered as a fruitful and logical research strategy in the search for novel analgesic and anti-inflammatory drugs. ${ }^{8}$

Currently Non-Steroidal Anti-Inflammatory Drugs (NSAIDs) and steroidal anti-inflammatory are used in the treatment of inflammation. Existing synthetic molecule likes NSAIDs and selective COX-2 inhibitors have potential to increase the incidence of adverse cardiovascular thrombotic effects. ${ }^{9}$ On the other hand steroids have immense potential in the treatment of inflammation, but due to their adverse effects it can be used only for short periods. ${ }^{10} \mathrm{So}$, in order to overcome these drawbacks, there is need to focus on the scientific exploration of herbal drugs having fewer side effects. The genus Clerodendrum (Family: Verbenaceae) is very widely distributed in tropical and subtropical regions of the world. More than five hundred species of this genus have been identified till now, which includes small trees, shrubs and herbs. Ethno-medical importance of various species of Clerodendrum genus has been reported in various indigenous systems of medicines and also as folk medicines. The genus is being used as medicines especially in countries like India, China, Thailand, Korea and Japan as an indigenous system of medicine for the treatment of various life threatening diseases such as syphilis, typhoid, cancer, jaundice and hypertension. Few species of the genus like Clerodendrum inerme, $C$. thomosonae, $C$. indicum, and $C$. speciosum are ornamental and being cultivated for aesthetic purposes. The powder/paste form and the various extracts of root, stem and leaves are reported to be used as medicine for the treatment of asthma, pyreticosis, cataract, malaria, and diseases of skin and lungs. In order to prove these ethnopharmacological claims, some of these plant species are being extensively studied for their pharmacological activities using various animal models. Along with biological studies, its isolation and identification studies of chemical constituents and its correlation with the biological activities of the genus has also been studied. ${ }^{11}$ Hence the rationale of the study was to carry out acute anti-inflammatory activity of ethanolic extract of the leaves of Clerodendrum viscosum (EELCV) by carrageenin induced paw oedema in wistar albino rats. 


\section{MATERIALS AND METHODS}

Institutional Animal Ethical Committee approval was obtained on 6th May, Ref. No. Ph.D 1/2010 from Yenepoya University, Derlakatte, Mangalore, India, before conducting the experiments.

\section{Plant Material}

In the month of June - August 2010, the whole plant was collected from rural area of Manjanady located in Mangalore district. It was authenticated by (Prof) Dr. Krishna Kumar G, Chairman, Dept of Applied Botany, Mangalore University, Mangalore, Karnataka, India. The herbarium of the plant (voucher specimen no YU/CV/2010) has been deposited at Museum of Department of Pharmacology, Yenepoya Medical College, Yenepoya University, Mangalore, Karnataka, India.

\section{Extraction}

Leaves of Clerodendrum viscosum were carefully separated, cleaned, shade dried, mechanically grinded and coarsely powdered. About 1000 gm of air dried powdered material was extracted with $90 \%$ ethanol in a soxhlet extractor for 36 hours. It was concentrated to dryness under reduced pressure and controlled temperature (40$50^{\circ} \mathrm{C}$ ) using rotary evaporator. The ethanolic extract yielded a dark green slightly viscous mass weighing $155 \mathrm{~g}$. The ethanolic extract was concentrated by vacuum distillation to dryness; the yield obtained was $15.5 \% \mathrm{w} / \mathrm{w}$ with respect to dried leaf. The collected leaf extract was stored in a desiccator.

\section{Sample Size, Grouping and Dose of the Drugs}

Animals were divided into 5 groups (Control, Standard and 3 groups of Test drug) containing 10 animals, making a total number of 50 animals.

\section{Drugs and Chemicals}

The standard Indomethacin was obtained from our institutional pharmacy, and $1 \%$ gum acacia from Department of Pharmacology, Yenepoya Medical College, Mangalore, Karnataka, India.

Table 1: Acute Anti-Inflammatory effect of Ethanolic Extract of leaves of Clerodendrum viscosum (EECLV) by Carragenin Induced Paw Oedema in Wistar Albino rats

\begin{tabular}{|c|c|c|c|c|c|c|}
\hline Drugs & $\mathbf{0 h r}$ & $\mathbf{1}^{\text {st }} \mathbf{h r}$ & $\mathbf{2}^{\text {nd }} \mathbf{h r}$ & $\mathbf{3}^{\text {rd }} \mathbf{h r}$ & $\mathbf{4}^{\text {th }} \mathbf{h r}$ & $\mathbf{6}$ Inhibition at \\
$\mathbf{3} \mathbf{h r}$
\end{tabular}

$\mathrm{n}=10$. The observation are mean \pm S.E.M. ${ }^{*} \mathrm{p}>0.05, * *<0.05, * * * \mathrm{p}<0.01$ as compared to control (ANOVA followed by Dunnett's multiple comparison test), EELCV- Ethanolic Extract of Leaves of Clerodendrum viscosum, p.o - Per Orally

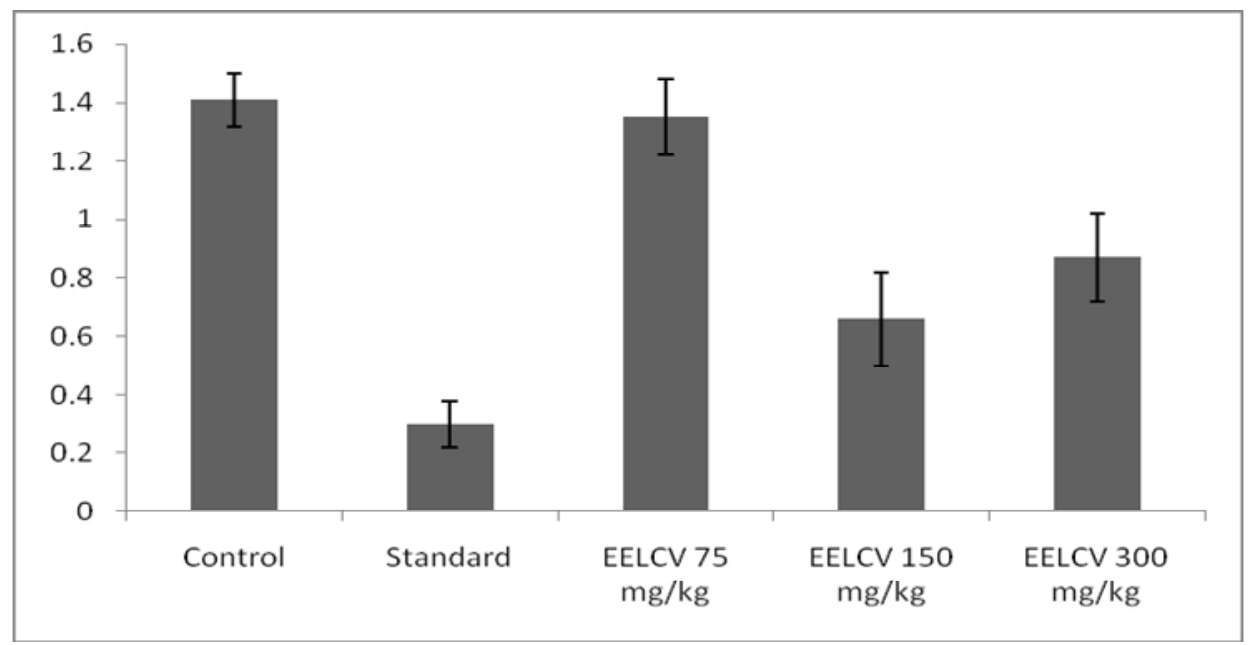

Graph 1: Anti-Inflammatory effect of Ethanolic Extract of leaves of Clerodendrum viscosum (EECLV) by Carragenin Induced Paw Oedema in Wistar Albino rats at $3^{\text {rd }} \mathbf{h r}$

The observations are mean \pm S.E.M. as compared to control (ANOVA followed by Dunnett's multiple comparison test) EELCV- Ethanolic Extract of Leaves of Clerodendrum viscosum 


\section{Anti-inflammatory activity by Carrageenin induced rat paw oedema}

In this method, rats were divided in to five groups of 10 animals each (Equal number of Male and Female). All the animals were pretreated with drugs / vehicle, 60 minutes before injection of carrageenin $(0.1 \mathrm{ml}$ of $1 \%)$. Carrageenin was injected into the sub plantar tissue of left hind paw of each rat. Swellings of carrageenin injected foot were measured at zero, first, second, third, fourth and sixth hour using Digital Plethysmometer. ${ }^{12,13}$ The right hind paw was injected with $0.1 \mathrm{ml}$ of Normal Saline (vehicle). The animals which received indomethacin (10 $\mathrm{mg} / \mathrm{kg}$, p.o.) served as reference standard. Control group received $1 \%$ gum acacia $3 \mathrm{ml} / \mathrm{kg}$ p.o. Three doses of the test drug were selected $(75,150$ and $300 \mathrm{mg} / \mathrm{kg}$ ) for test group of rats, and all the groups were subjected to screening for evaluating acute anti-inflammatory activity. The peak effect of the carrageenin induced paw oedema was observed at the $3^{\text {rd }}$ hour after the injection. The increase in paw volume at $3^{\text {rd }}$ hour was calculated as percentage compared with the volume measured immediately after injection of carageenin for each animal and collected data were compared between groups.

\section{Statistical Analysis}

Results are expressed as mean \pm SEM. Statistical analysis was performed using one-way analysis of variance (ANOVA) followed by Dunnett's Multiple Comparison test. $\mathrm{p}<0.05$ was considered statistically significant.

\section{RESULTS}

Oral administration of EELCV at doses of 150 and $300 \mathrm{mg} / \mathrm{kg}$ showed significant $(\mathrm{p}<0.01)$ and moderately significant anti-inflammatory activity $(\mathrm{p}<0.05)$ respectively by carrageenin induced paw oedema in Wistar Albino rats (Table 1 and Figure 1). The percentage inhibition of the oedema at $3^{\text {rd }}$ hour was $53.19 \%$ and $38.29 \%$ at the dose of $150 \mathrm{mg} / \mathrm{kg}$ and $300 \mathrm{mg} / \mathrm{kg}$ respectively compared to control and reference group (Table 1 and Figure 1).

\section{DISCUSSION}

Pain, inflammation and pyrexia are the most usual disturbing symptoms in day to day life. Plenty of drugs are available in the market for relieving these symptoms and which are also sold over the counter (OTC). However, they have high tendency of causing adverse drug reaction from a trivial nausea and vomiting to gastric irritation leading to peptic ulcer, perforation and may also even lead to death. ${ }^{14}$ The main undesirable side-effects of aspirin (Irreversible COX inhibitors) taken by oral route are gastrointestinal ulcers, stomach bleeding, and tinnitus, especially in higher doses. In children and adolescents, aspirin is no longer indicated to control flu-like symptoms or the symptoms of chickenpox or other viral illnesses, because of the risk of Reye's syndrome. ${ }^{15}$ Reversible COX inhibitors have not shown any superiority over aspirin in therapeutic effects of safety in over dose. Nimesulide has been banned in most western country due to its hepatotoxic effects. Even though paracetamol is commonly prescribed analgesic and antipyretic drug, but it lacks anti-inflammatory effects and also not safe in over dose. Selective COX 2 inhibitors have been least prescribed in last few years due to its adverse cardiac events and many have been withdrawn from the market. ${ }^{16}$ Corticosteroids even though have anti inflammatory effects, but lacks analgesic and antipyretic effects. Moreover the long term administration of corticosteroids has its own adverse effects and also delays wound healing process. ${ }^{17,18}$ In recent years, active principles of different chemical structures have been isolated from plants possessing anti-inflammatory activity. Southern part of our country has a tradition of using herbal preparation from centuries especially in dakshina kannada (Mangalore) district. However no scientific data are available for many herbal drugs which are locally used. Hence by evaluating these drugs, it would be worthwhile to have scientific approach of using them. Hence in this study, an indigenous plant called Clerodendrum viscosum mentioned in Charaka and Sushruta treaties as an analgesic, anti-inflammatory and antipyretic drug and also in folk medicine was taken to evaluate acute antiinflammatory activity of EELCV by carrageenin induced paw oedema in Wistar Albino rats. ${ }^{19}$ Preliminary phytochemical screening of EELCV showed the presence of phytosterols, tri-terpenoids, flavonoids, lactones, fats and fatty acid, glycoside, phenolic compound and tannins. $^{20}$ Phenolic compounds possess biological properties such as anti-apoptosis, anti-aging, anti-cancer, anti-inflammatory, anti-atherosclerosis, cardiovascular protection and improvement of endothelial function, as well as inhibition of angiogenesis and cell proliferation activities. ${ }^{21}$ Probably, presence of phenolic compounds could be the reason for its anti-inflammatory activity.

However further studies are required to evaluate its comprehensive analysis including quantitative / semi quantitative analysis, characterize its chemical structure and assess its pharmacotherapeutical activities with exact mechanism of action as an anti-inflammatory agent.

\section{ACKNOWLEDGEMENT}

The author is grateful to Dr. S. N. Rao, Senior Professor and Head, Dept of Pharmacology, and Yenepoya University for providing the support to conduct this experimental research.

\section{REFERENCES}

1. SK Raghav, B Gupta, C Agrawal, K Goswami, and HR Das. Antiinflammatory effect of Ruta graveolens L. in murine macrophage cells. Journal of Ethnopharmacology 2006;104(1-2) :234-239. http://dx.doi.org/10.1016/j.jep.2005.09.008 PMid:16207519

2. HP Rang, MM Dale, JM Ritter, RJ Flower and G Henderson. Pharmacology, Elsevier Churchill Livingstone, Edinburgh, UK, 7th edition, 2011. http://www.amazon.com/Rang-Dales-PharmacologySTUDENT-CONSULT/dp/0702034711

3. South African Medicines Formulary (SAMF), Health and Medical Publishing Group of the South African Medical Association, Cape Town, South Africa, 9th edition, 2010. http://www.hmpg.co.za/ samf-2012

4. GB Martini-Bettolo. Present aspects of the use of plants in traditional medicine. Journal of Ethnopharmacology.1980; 2(1):5-7 http://dx.doi.org/10.1016/0378-8741(80)90021-5

5. Kokate CK, Purohit AP, Gokhale SB. 2002. Textbook of pharmacognosy, Nirali prakasan: Pune. 18:1-4 p.

6. Trease GE, Evans MC. 1983. Text book of Pharmacognosy. 12th edition. Balliere, Tindall: London. P 343-383

7. Chopra RN. 1958. Indigenous drugs of India. Dhar publishers: Kolkata. 15:53-56

8. Gupta M, Mazumder UK, Gomathi P, Thamilselvan V. Antiinflammatory evaluation of leaves of Plumeria acuminate. BMC Complementary and alternative medicine. 2006, 6 (36):1472-6882. 
9. Miller TA. Protective effects of prostaglandins against gastric mucosal damage. Current knowledge and proposed mechanism. American J .Physiol 1983; 245:601-603

10. Chowdhury MA, Abdellatif KRA, Don Y, Das D, Suresh MR, Knaus EE. Synthesis of celecoxib analogues possessing a NDifluoromethyl-1,2-dihydropyrid-2-one s-Lipoxygenase pharmacophore: Biological evaluation as dual inhibitors of cyclooxygenases and 5-Lipoxygenase with anti-inflammatory activity. J Med Chem. 2009; 52:1525-1529 http://dx.doi.org/ 10.1021/jm8015188 PMid:19296694

11. Neeta Shrivastava, Tejas Patel. Clerodendrum and Heathcare: An Overview. Medicinal and Aromatic Plant Science and Biotechnology 2007; 1(1), 142-150.

12. Vogel HG. Drug discovery and evaluation, pharmacological assay, 2nd ed. New York: Springer; 2002. p. 670. http://dx.doi.org/ 10.1007/3-540-29837-1 9

13. Winter CA, Risley EA, Nuss GW. Carrageenan - induced edema in hind paw of rat as an assay for anti-inflammatory drugs. Proc Soc Expt Biol Med 1962; 111:544-7

14. Rajan Chandrashekar, Sudarshanram Narayan Rao. Acute Central and Peripheral Analgesic Activity of Ethanolic Extract of The Leaves Of Clerodendrum Viscosum (EECV) In Rodent Models. Journal of Drug Delivery and Therapeutics; 2012; 2(5):105-108

15. Macdonald S. Aspirin use to be banned in under 16 year olds. BMJ. 2002; 325(7371):988.http://dx.doi.org/10.1136/ bmj.325.7371.988/c PMid:12411346 PMCid:1169585
16. Kearney $\mathrm{P}$ M, Baigent C, Godwin J, Halls H, Emberson J R, Patrono C. Do selective cyclo-oxygenase-2 inhibitors and traditional non-steroidal anti-inflammatory drugs increase the risk of atherothrombosis? Meta-analysis of randomized trials. BMJ (Clinical research ed.) 2006; 332.

17. Mehlisch DR. The efficacy of combination analgesic therapy in relieving dental pain. Journal of American Dental Association. 2002; 133(7):861-71.

18. Janssen P, Niemegeers CJE, Dony JGH. The inhibitory effect of fentanyl and other morphine like analgesics on the warm water induced tail withdrawl reflex in rats. Arzneim Forsch.1963; 13:502507.

19. Sharma HK, Chhangte L, Dolui AK. Traditional medicinal plants in Mizoram, India. Fitoterapia.2001;72 (2): 146-161. http://dx.doi.org /10.1016/S0367-326X(00)00278-1

20. Chandrashekar. R, Rao S.N. Phytochemical Analysis of Ethanolic Extract of Leaves of Clerodendrum Viscosum (EELCV).WJPPS 2012; 1(3):1092-1099.

21. Yadav RNS, Munin Agarwala. Phytochemical analysis of some medicinal plants. Journal of Phytology. 2011; 3(12): 10-14

\section{Cite this article as:}

Chandrashekar R, Rao S.N. Acute anti-inflammatroy activity of ethanolic extract of leaves of Clerodendrum viscosum by carrageenin induced paw oedema method in wistar albino rats. Int. J. Res. Ayurveda Pharm. 2013; 4(2):224-227 